\title{
Unsaturated Shear Strength of Compacted Clayey Soil via Suction-controlled Ring Shear Testing
}

\author{
Laureano R. Hoyos ${ }^{1 *}$, Jairo E. Yepes ${ }^{2}$, Claudia L. Velosa ${ }^{3}$, and Anand J. Puppala ${ }^{4}$ \\ ${ }^{1}$ Professor, University of Texas at Arlington, Arlington, Texas 76019, USA \\ ${ }^{2}$ Former Visiting Research Scholar, Texas A\&M University, College Station, Texas 77842, USA \\ ${ }^{3}$ Former Graduate Research Assistant, University of Texas at Arlington, Arlington, Texas 76019, USA \\ ${ }^{4}$ Professor, Texas A\&M University, College Station, Texas 77842, USA
}

\begin{abstract}
An experimental program has been undertaken to assess both peak and residual shear strength parameters of statically compacted, moderate plasticity clayey soil under suction-controlled conditions, resulting in a defined set of suction-dependent peak and residual failure envelopes over a relatively wide range of suction states, from 0 to $300 \mathrm{kPa}$. The experimental program was accomplished in a servo/suctioncontrolled ring shear apparatus, which is suitable for testing unsaturated soils under large deformations via the axis-translation technique. Test results substantiate the crucial role that has been observed to be played by the imposed matric suction on the residual shear strength of compacted clayey soils. For the range of net normal stress (0-200 kPa) and matric suction (0-300 kPa) states investigated, the increase in either peak or residual shear strength, with increasing matric suction, was found to be manifestly nonlinear. Furthermore, a distinct correspondence was observed between the nonlinearity of the peak shear strength envelope, with respect to increasing matric suction, and the soil-water retention properties of the clayey soil. Results, in general, suggest that a conceptual residual shear strength framework for unsaturated soils, similar to that postulated for peak shear strength, can eventually be formulated as more experimental evidence of this kind is made available.
\end{abstract}

\section{Background and scope}

Despite the crucial importance of peak and residual shear strength properties of compacted clayey soils for the analysis and design of geotechnical infrastructure resting on unsaturated ground and/or made of unsaturated soils, there is limited experimental evidence of unsaturated soil behaviour under large deformations as the soil is being subjected to controlled matric suction states. This type of research has been deterred by the lack of suitable testing tools and techniques. It is in this context that a suctioncontrolled ring shear (RS) apparatus plays a fundamental role in a thorough assessment of peak and residual shear strength properties of this type of geomaterials.

In recent years, a few researchers have expanded the capabilities of Bromhead-type RS devices for soil testing under suction-controlled conditions via vapor-transfer or axis-translation technique [1-4]. A comprehensive effort, however, has yet to be undertaken to produce a thorough set of suction-dependent peak/residual failure envelopes for compacted clayey soil under a relatively wide range of suction states. The present work is motivated by these research needs.

In the present work, an experimental program has been undertaken to assess both peak and residual shear strength parameters of statically compacted samples of low plasticity clayey soil (CL) under suction-controlled conditions $(0-300 \mathrm{kPa})$. The work was accomplished in a servo/suction-controlled RS apparatus that is suitable for testing unsaturated soils under large deformations via the axis-translation technique [5].

The development of the apparatus, including details of its main components, step-by-step assembling, and its performance verification against a Bromhead-type RS apparatus, is presented by Hoyos et al. [5]. A preliminary series of suction-controlled RS tests was accomplished on statically compacted samples of silty sand (SM) with the aim of trouble-shooting the entire system. Although silty sand is not an ideal soil for RS testing, the residual friction angle with respect to suction (i.e., residual beta angle) was found to remain virtually constant, regardless of the applied level of net normal stress.

More recently, Hoyos et al. [6] conducted a series of tests on statically compacted samples of silty clayey sand (SC-SM) by using the same servo/suction-controlled RS apparatus featured in the present work. The increase in residual shear strength with increasing suction was found to be significantly nonlinear for SC-SM soil. Multi-stage test results also seemed to substantiate that the residual shear strength of compacted soils is not dependent on the pre-shearing or suction history undergone by the soil.

The following sections are devoted to documenting the most recent observations from suction-controlled RS testing on statically compacted, low plasticity clay (CL).

Corresponding author: hoyos@uta.edu 


\section{Suction-controlled RS apparatus}

The RS apparatus consists of three modules: (1) Main cell with rotational shear system, including pneumatic and electromechanical rotary actuators for application of normal load and torque, respectively; (2) DA/PC system, with performance and data reduction software for realtime calculation of normal and shear stresses and linear and angular displacements; and (3) PCP-15U suction control panel to conduct axis-translation technique [5].

The specimen is statically compacted into the bottom annular platen, which features a full set of 5-bar HAE ceramic disks, via the upper annular platen affixed to the top of a vertical shaft: Figures 1(a)-(c). All drainage and flushing lines are filled with de-aired water and flushed several times to avoid trapped air in the whole system. The main RS cell is then set into place and the top cover plate affixed to the cell: Figure 1(d). A pore-air pressure line from the PCP-15U panel is connected to the cover plate via a quick connector: Figure 1(d). The specimen is then subject to suction-controlled, multi-stage RS testing via axis-translation technique $\left(\mathrm{u}_{\mathrm{w}}=0\right)$.
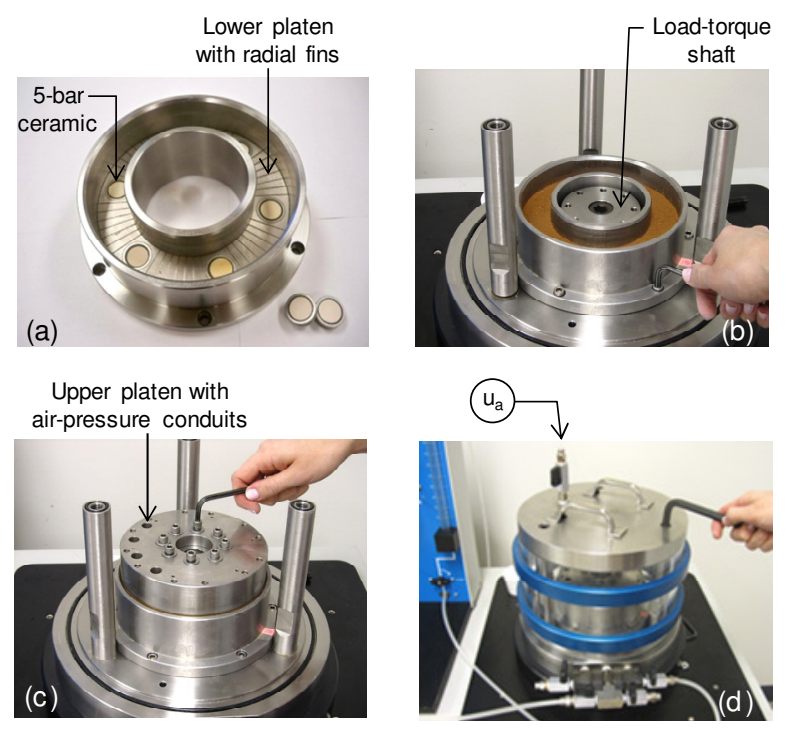

Fig. 1. Assembling of suction-controlled RS apparatus.

\section{Test soil and compaction properties}

The test soil classifies as silty clay (CL) according to the USCS. The soil has $18 \%$ sand, $50 \%$ silt, and $32 \%$ clay; optimum moisture content, $\mathrm{OMC}=17 \%$, and maximum Proctor dry density, $\gamma_{\mathrm{d}-\max }=1.77 \mathrm{~g} / \mathrm{cm}^{3}$. The fine-grained fraction yields a liquid limit, $\mathrm{LL}=37 \%$, and a plasticity index, $\mathrm{PI}=20 \%$. The specific gravity is 2.72 . The drying loop of the corresponding soil-water characteristic curve (SWCC), assessed via pressure plate testing, is shown in Figure 2, along with the best-fitting model curve as per Fredlund and Xing [7].

The SWCC was crucial in defining the appropriate range of suction states (beyond the air-entry value of the test soil) to be induced on compacted specimens of CL soil. SWCCs for SM and SC-SM soils, previously tested by Hoyos et al. [5, 6], are also included for reference and comparison purposes.

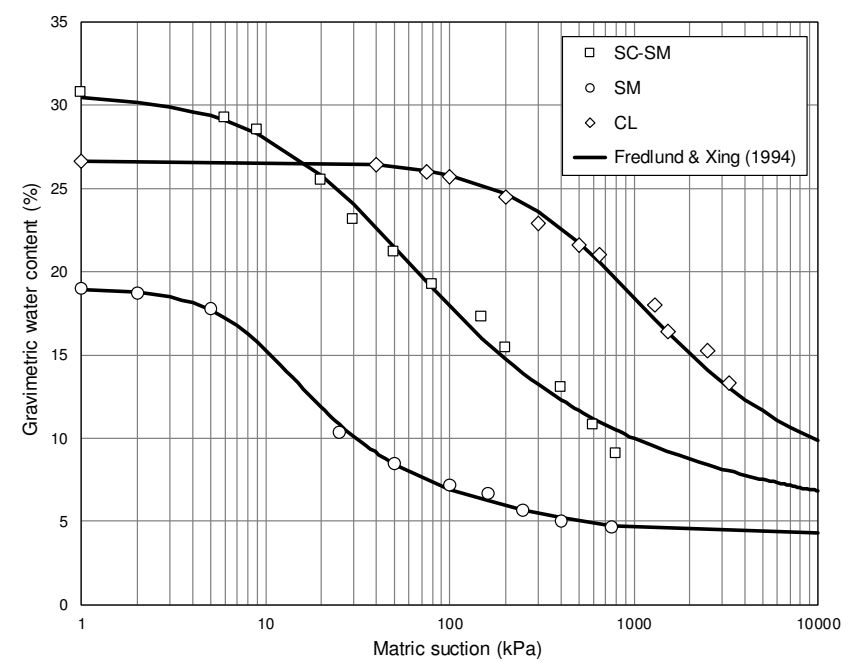

Fig. 2. SWCCs from compacted SM, SC-SM and CL soils.

\section{Shear strength properties of CL soil}

In the present work, the assessment of peak and residual shear strength of compacted CL soil was accomplished under net normal stresses, $\left(\sigma_{\mathrm{n}}-\mathrm{u}_{\mathrm{a}}\right)$, ranging from 25 to $200 \mathrm{kPa}$, and for constant matric suction states, $\left(\mathrm{u}_{\mathrm{a}}-\mathrm{u}_{\mathrm{w}}\right)$, ranging from 25 to $200 \mathrm{kPa}$. Shearing under a sustained net normal stress and matric suction state was terminated when it was readily apparent that a residual stress had been reached. (Previous performance verification tests showed that the apparatus yields reasonably repeatable results via axis-translation technique [5].)

Suction-controlled RS testing was conducted at an average horizontal displacement rate of $0.025 \mathrm{~mm} / \mathrm{min}$, which corresponds to a rotational speed of $0.023 \% \mathrm{~min}$. This shearing rate is slightly lower than that used in previous works where significantly higher suction values (up to $100 \mathrm{MPa}$ ) were induced via relative humiditybased technique $[1,4]$.

Figure 3 shows the effect of matric suction on both the position and slope of peak failure envelopes obtained for compacted CL soil. The patterns are similar to those observed for compacted SC-SM soil by Hoyos et al. [6]: Envelopes essentially linear, higher position for $200-\mathrm{kPa}$ suction, lower apparent cohesion for $25-\mathrm{kPa}$ suction, and peak friction angle virtually constant.

Likewise, Figure 4 shows the effect of matric suction on the position and slope of residual failure envelopes obtained for compacted CL soil. The patterns are similar to those observed in the peak failure envelopes obtained for compacted CL soil (Figure 3) and SC-SM soil [6]: envelopes essentially linear, higher position for $200-\mathrm{kPa}$ suction, lower residual cohesion for $25-\mathrm{kPa}$ suction, and residual friction angle virtually constant, particularly at higher suction values.

Figure 5 shows the effect of net normal stress on the peak failure envelopes as projected onto the residual shear stress vs. matric suction plane. Results show a high nonlinearity of the peak strength envelope with respect to matric suction. 


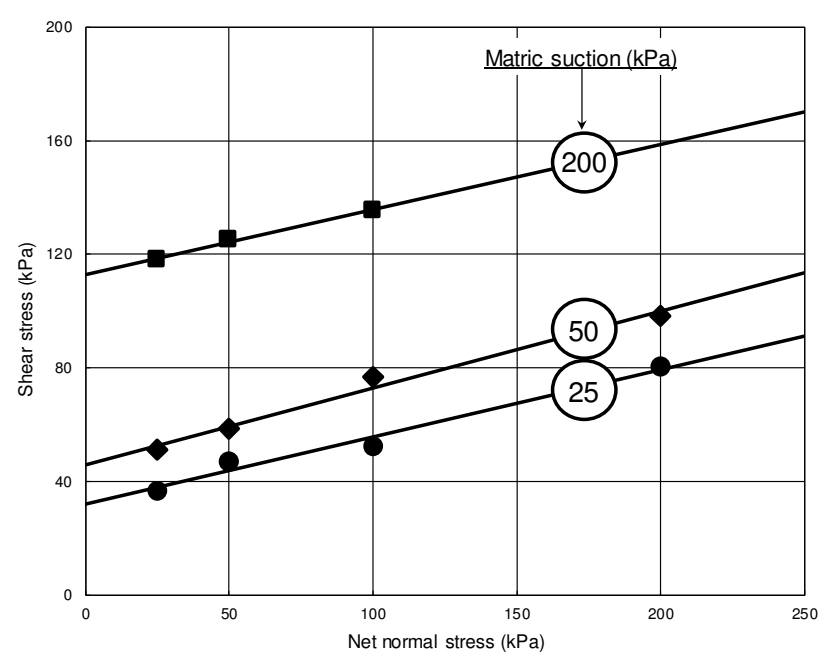

Fig. 3. Peak failure envelopes from compacted CL soil.

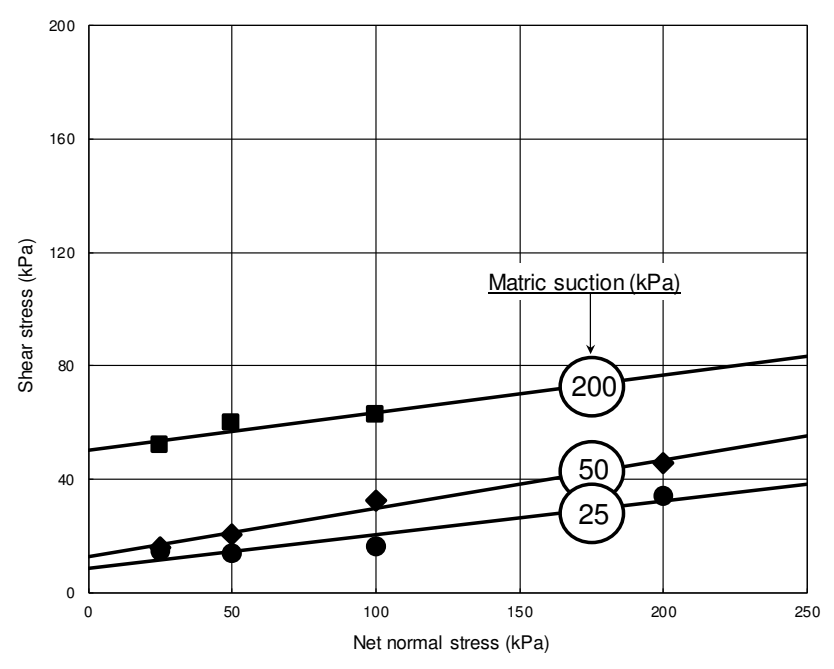

Fig. 4. Residual failure envelopes from compacted CL soil.

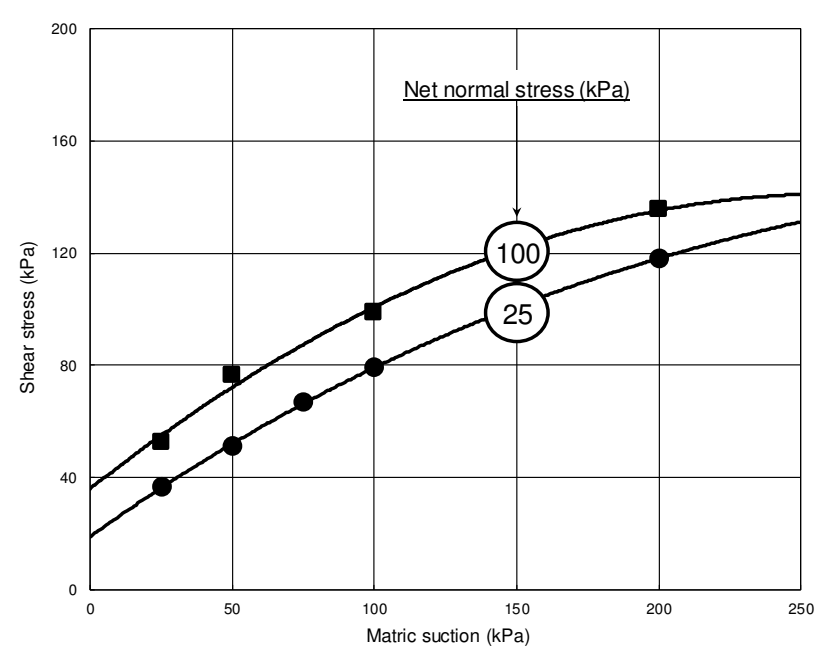

Fig. 5. Nonlinearity of peak failure envelopes from CL soil.
As demonstrated by Vanapalli et al. [8] and Lu and Likos [9], there is a direct correspondence between the nonlinear nature of the peak shear strength envelope of unsaturated soils, with increasing matric suction, and the corresponding SWCC. Within the regime of relatively low suction, and prior to the air-entry pressure, the soil pores remain essentially saturated, the shear strength envelope is reasonably linear, and the beta angle $\phi^{\mathrm{b}}$ is effectively equal to the friction angle $\phi^{\prime}$.

As the soil becomes unsaturated, the reduction in the pore-water volume within this regime effectively reduces the contribution of matric suction toward shear strength. This effect is more noticeable as the net normal stress increases. The patterns observed in Figure 5 may be best explained by this essential feature of hydro-mechanical behaviour of unsaturated soils.

The SWCC from CL soil (Figure 2) shows an airentry value of approximately $200 \mathrm{kPa}$, beyond which the nonlinearity of the peak failure envelope indeed becomes increasingly manifest (Figure 5). One could only expect that the same phenomenon would be replicated when it comes to residual envelopes, as currently investigated by the present authors.

\section{Concluding remark}

Results from suction-controlled RS tests on compacted CL soil suggest that a conceptual residual shear strength framework for partially saturated soils, similar to the one postulated for peak shear strength [10], could eventually be formulated as more experimental evidence of this kind become available.

\section{Acknowledgements}

The core system of the RS apparatus used in this experimental effort was developed under U.S. National Science Foundation (NSF) Award No. CMS-0626090. This support is gratefully acknowledged. Any findings, conclusions, or recommendations expressed in this material are those of the authors and do not necessarily reflect the views of the Foundation.

\section{References}

1. J. Vaunat ,C. Amador, E. Romero, and I. DjerenMaigre, "Residual strength of a low plasticity clay at high suctions." Proceedings of Fourth International Conference on Unsaturated Soils, Carefree, Arizona, vol. 1, 1279-1289 (2006)

2. J. Vaunat, V. Merchán, E. Romero, and J. Pineda, "Residual strength of clays at high suctions." Proceedings of the Second International Conference on Mechanics of Unsaturated Soils, Weimar, Germany, vol. 2, 151-162 (2007)

3. J.A. Infante-Sedano, S.K. Vanapalli, and V.K. Garga, Geotechnical Testing Journal, ASTM, 30, 1, 1-9 (2007)

4. V. Merchán, E. Romero, and J. Vaunat, Geotechnical Testing Journal, ASTM, 34, 5, 433-444 (2011)

5. L.R. Hoyos, C.L. Velosa, and A.J. Puppala, Geotechnical Testing Journal, ASTM, 34, 5, 413-423 (2011) 
6. L.R. Hoyos, C.L. Velosa, and A.J. Puppala, Engineering Geology, 172, pp. 1-11 (2014)

7. D.G. Fredlund, and A. Xing, Canadian Geotechnical Journal, 31, 521-532 (1994)

8. S.K. Vanapalli, D.G. Fredlund, D.E. Pufahl, and A.W. Clifton, Canadian Geotechnical Journal, 33, 3, 379-392 (1996)

9. N. Lu, and W.J. Likos, Unsaturated soil mechanics, (John Wiley \& Sons, Hoboken, N.J, 2004)

10. D.G. Fredlund, and H. Rahardjo, Soil Mechanics for Unsaturated Soils (John Wiley and Sons, New York, 1993) 